\title{
A PRODUÇÃO ORGÂNICA DE ARROZ, UMA INOVAÇÃO NA PRODUÇÃO QUE GANHA ESPAÇO NO MERCADO
}

\author{
Ana Carolina Cozza Josende da Silva (PPGEP/UFSM) anacarolina_cj@yahoo.com.br \\ Roselaine Ruviaro Zanini (PPGEP/UFSM) rrzanini@terra.com.br
}

\begin{abstract}
Resumo: Este artigo tem como finalidade e objetivo apresentar através de teorias e as novidades já publicadas sobre o tema de produção orgânica a importância e a inovação que ela representa, além de demonstrar seu crescimento nos últimos anos. $O$ estado do Rio Grande do Sul é o maior produtor brasileiro em arroz, sendo que a grande parte é a produção convencional, com grandes áreas e uso intensivo de maquinário e insumos. Então, surge a inovação para contribuir na diminuição dos impactos ambientais que vem ocorrendo, essa inovação é uma preocupação com o meio ambiente com a produção de arroz orgânico. Esta pesquisa ocorreu por meio de pesquisa bibliografia sendo somente esta metodologia utilizada. Durante o decorrer deste trabalho foram pesquisados diversos autores que tratam o tema de produção orgânica e o crescimento da mesma nos últimos anos. Neste sentido, será apresenta especificamente o caso da Cooperativa de Produção Agropecuária Nova Santa Rita Ltda. - COOPAN.
\end{abstract}

Palavras-chave: Inovação. Produção de Arroz. Orgânica.

\section{Introdução}

Atualmente, o mercado orgânico brasileiro vem crescendo muito a cada ano. Ele é importante para o país, pois se trata de uma produção que preserva o meio ambiente, bom para a saúde, além de gerar emprego e renda para o trabalhador rural. Para isso, é necessário que esses produtores definam formas competitivas para o mercado, focalizando os aspectos que realmente agregam valor para os clientes.

No Brasil, a produção de alimentos orgânicos tem registrado crescimento médio de $50 \%$ ao ano, a maior parte da produção nacional está localizada nos estados do Sudeste $(60,2 \%)$ e Sul $(25,2 \%)$, seguido pelo Nordeste $(8,6 \%)$, Centro-Oeste $(3,3 \%)$ e Norte $(2,6 \%)$ (OKUDA, 2002). A produção orgânica brasileira ocupa atualmente uma área, com maior uso de mão de obra e uma dependência menor de recursos externos (ORMOND et al., 2002).

No Rio Grande do Sul o produtor rural e sua família, sobretudo o pequeno, conta com o apoio de Órgãos Governamentais como o Instituto de Assistência Técnica e Extensão Rural do Rio Grande do Sul - EMATER/ RS, que está voltado para o fortalecimento dos agricultores familiares e suas organizações buscando 
garantir a segurança alimentar e a inclusão social através da transferência de tecnologias autossustentáveis e inovadoras (EMATER, 2012). E tem como missão promover o Desenvolvimento Rural sustentável por meio de ações de assistência técnica e extensão rural, mediante processos educativos e participativos, visando o fortalecimento da agricultura familiar e suas organizações e criando condições para o pleno exercício da cidadania e a melhoria da qualidade de visa da população gaúcha.

Nesse mercado, quase toda a comercialização de produtos orgânicos é realizada através da venda direta ou em feiras, que em geral, têm como clientes consumidores mais informados sobre a qualidade do produto. Contudo, um novo cenário formou-se com a entrada das grandes redes de supermercados que vêm se destacando como um forte canal de comercialização desses produtos (SCHMIDT, 2001).

A comercialização dos produtos orgânicos é um processo complexo para os produtores, pois exige conhecimentos administrativos, capacidade gerencial e um planejamento de produção apropriado para atender às necessidades dos clientes, além de que os produtores geralmente apresentam dificuldade para se organizar em associações ou cooperativas. $\mathrm{O}$ processo de comercialização desses produtos também envolve várias fases como a limpeza, classificação, embalagens, distribuição e a certificação que inclui os custos de análises e auditorias, o que contribui para encarecer os produtos orgânicos. Além disso, os estabelecimentos comerciais praticam altas margens de contribuição que são maiores do que as mar- gens dos produtos convencionais, pelo fato de estarem oferecendo um produto diferenciado (DAROLT, 2001).

\section{Produção Orgânica}

A Produção Orgânica não é uma ideia recente, pois se considera como orgânica praticamente toda a agricultura realizada com baixa tecnificação, ou por quem não tem acesso a insumos (BRASIL, 2007). Porém, a ideia central desta atividade é ser livre de agrotóxicos. Esse é o grande propulsor do movimento. Agricultura Orgânica inseriu a ideia de evitar uso de venenos e outros valores, como o equilíbrio ambiental, o respeito aos trabalhadores, o ato de evitar adubos de alta solubilidade, e o aumento da qualidade do produto (BRASIL, 2011).

Inicialmente, o termo agricultura orgânica foi usado para designar uma forma alternativa de agricultura, que objetivava contrapor-se à agricultura tradicional. Dessa forma, a agricultura orgânica reúne todos os modelos não convencionais de agricultura, tais como: biodinâmica, natural, biológica, permacultura ou agroecológica, para se contrapor ao modelo convencional (SOUZA FILHO, 2001). Atualmente, o artigo $1^{\circ}$ da Lei de $n^{\circ} 10.831$, de 23 de dezembro de 2003, especifica a abrangência da agricultura orgânica através da definição de sistema orgânico.

Considera-se sistema orgânico de produção agropecuária, todo aquele em que se adotam técnicas específicas, mediante a otimização do uso dos recursos naturais e socioeconômicos disponíveis e o respeito à integridade cultural das comunidades rurais. Tendo por objetivo à 
sustentabilidade econômica e ecológica, a maximização dos benefícios sociais, a minimização da dependência de energia não renovável, empregando sempre que possíveis métodos culturais, biológicos e mecânicos. Em contraposição ao uso de materiais sintéticos, a eliminação do uso de organismos geneticamente modificados e radiações ionizantes, em qualquer fase do processo de produção, processamento, armazenamento, distribuição e comercialização. E a proteção do meio ambiente (BRASIL, 2007).

A mesma lei define como produto orgânico "aquele obtido em sistema orgânico de produção agropecuária ou oriundo de processo extrativista sustentável e não prejudicial ao ecossistema local”. Dessa forma, para que um produto seja considerado orgânico, este deve ter, em toda a sua cadeia produtiva, a preocupação com as exigências feitas na Lei 10.831, de 23 de dezembro de 2003, não bastando ter essa preocupação apenas na produção da matériaprima, mas durante todo o processo agroindustrial (BRASIL, 2011).

Nos produtos orgânicos, a certificação é a forma de controle de sua procedência e de sua diferenciação na forma produtiva, em relação à convencional, ressaltando os atributos de qualidades dos produtos orgânicos. Assim como a ausência de resíduos tóxicos e a presença de extremidades positivas ao meio ambiente, em seu processo produtivo, dificilmente observáveis na hora da compra, e que podem possibilitar ações oportunistas por parte dos vendedores (SOUZA, 2000).
A certificação é uma atividade importante que visa a contribuir para a confiabilidade da produção orgânica. Certificação é a definição de atributos de produtos, processos ou serviços e a garantia de que eles se enquadrem em normas predefinidas, é uma ferramenta que oferece procedimentos e padrões básicos para as empresas gerenciarem o nível de qualidade de seus produtos e garantirem um conjunto de atributos. Do lado da demanda, busca informar ao consumidor que aquele determinado produto tem os atributos por ele procurados (NASSAR, 1998).

A certificação, nesse caso, constitui um elemento de redução da forte assimetria de informações existentes entre vendedores e consumidores, dificultando a adoção de práticas oportunistas, motivadas pela possibilidade do preço-prêmio, normalmente atribuído aos orgânicos (SOUZA, 2000).

No Brasil, os pioneiros na certificação de produtos orgânicos são o Instituto Biodinâmico de Desenvolvimento Rural (IBD), sediado em Botucatu (SP), avalizado pelo IFOAM, e cujo selo é aceito em mercados internacionais; e a Associação de Agricultura Orgânica (AAO), cujo selo é aceito nacionalmente. Outras certificadoras nacionais que atuam regionalmente são: a Associação de Agricultura Nacional de Campinas e Região (ANC); a Associação dos Produtores de Agricultura Natural (APAN); a Fundação Mokite Okada (MOA); a COOLMÉIA, no Rio Grande do Sul; e a Associação de Agricultores Biológicos do Rio de Janeiro (ABIO). Atualmente, existem aproximadamen- 
te 25 selos de certificadoras no país (Brasil, 2011).

\section{Inovação}

A inovação ambiental ou eco-innovation é um conceito recente no contexto de inovação, e se começou a discutir o assunto a partir da década de 1990 (KEMP; PEARSON, 2007). O que distingue inovação ambiental do conceito de inovação tradicional é o fato que a primeira abrange os ganhos ambientais gerados quando comparados com outras tecnologias (KEMP; ARUNDEL, 1998). A OCDE (2003) define inovação como a transformação de uma ideia em um produto novo ou melhorado que se introduz no mercado; ou em novos sistemas de produção; ou em difusão, comercialização e utilização. No conceito, é possível perceber que a inovação envolve um processo e que esta poderá resultar em produtos ou serviços finais. Em organizações nas quais a inovação é uma fonte de vantagem competitiva, a estratégia de "coopetição" tem papel importante, de tal forma que novos produtos, processos de produção, formas organizacionais e novos mercados são eficazmente competitivos. Isso ocorre devido ao aumento do acesso a novos conhecimentos, à aprendizagem organizacional, às novas tecnologias, aos produtos complementares, permitindo ampliar a capacidade tecnológica e o processo de inovação (JORDE; TEECE, 1989).

\section{O Arroz Orgânico que Ganhou Mer- cado}

Como já citado, esta pesquisa será um estudo de caso realizado junto à Cooperativa de Produção Agropecuária Nova Santa Rita Ltda. COOPAN, esta, formada por integrantes do assentamento Capela. Foi fundada em 30 de junho de 1995 por um grupo de famílias que acreditaram na forma coletiva de organização econômica e social da produção, agra industrialização e comercialização dos frutos de seu trabalho. A sede da Cooperativa fica localizada na agrovila e no seu entorno estão as moradias onde vivem as famílias, próximas dos estabelecimentos de produção e industrialização de suínos e o engenho de arroz. A Cooperativa tem como atividades principais a produção de arroz, leite, criação e abate de suínos. O local é considerado modelo no Brasil, e lá estão assentadas 100 famílias que produzem através de um modelo de cooperativa.

Ainda sobre comercialização dos produtos orgânicos, houve no mês de setembro do ano de 2012 a maior venda de um produto da reforma agrária a uma rede de supermercados, onde foi celebrada em um evento paralelo ao Rio+20. A Cooperativa de Produção agropecuária Nova Santa Rita Ltda., objeto de estudo nesta pesquisa, e o Grupo Pão de Açúcar firmaram um acordo que garante o fornecimento de 15 toneladas de arroz orgânico até dezembro. O produto irá ficar a disposição dos clientes nas lojas do grupo na Região Centro-Oeste. O contrato irá beneficiar diretamente 30 famílias de assentados no Rio Grande do sul e indiretamente chegará a atingir 700 famílias assentadas já que a Coopan integra a Cooperativa Regional dos Assentados da Região de Porto 
Alegre - Cootap.

Fala-se então sobre a comercialização deste tipo de produção ligada a esta comercialização deve-se falar na competitividade existente na produção de produtos orgânicos, mais especificamente o arroz orgânico. Hoje no Brasil, sabe-se que a competitividade é muito acirrada em qualquer setor da economia, mesmo assim, sabe-se do crescimento e desenvolvimento da Cooperativa em estudo.

Sabendo que a competitividade refere-se ao modo como uma empresa se posiciona em relação ao mercado consumidor frente a sua concorrência (DAVIS et al., 2001), e é muito importante para definir se uma empresa irá progredir ou falir (STEVENSON, 2001). Portanto, é indispensável conseguir vantagem sobre os concorrentes para sobreviver e vencer. Quando uma empresa é bem administrada aumenta a probabilidade de alcançar sucesso e a liderança no mercado (BATEMAN; SNELL, 1998).

Uma nova situação econômica tem se caracterizado pela determinação dos consumidores em se relacionar com empresas que prezam pela ética, pela preservação da natureza e por uma boa imagem institucional no mercado (ANDRADE et al., 2002). Seguindo essa tendência, a agricultura orgânica tem se destacado pela transformação que vem ocorrendo no campo.

Se antes essa atividade era desenvolvida basicamente em pequenas propriedades rurais, atualmente os grandes produtores também foram atraídos por esse mercado que cresce de $30 \%$ a $50 \%$ ao ano no Brasil, movimentando trezentos milhões de dólares (KISS, 2004).
Pensando nesses fatos, existem algumas pesquisas sobre o assunto, como a de Rodrigues \& Rodrigues (2002) realizada nas cidades de Catanduva e São José do Rio Preto - Brasil, o resultado da pesquisa indicou que $63 \%$ dos consumidores entrevistados afirmaram estar preocupados com a qualidade dos alimentos que consomem. Os pesquisadores também ressaltaram que o produto orgânico tem obtido um grande destaque na mídia e que a sua comercialização encontra-se em fase de crescimento.

Outra pesquisa também relevante é a de Tacconi (2004) realizada com consumidores que compram hortifrúti orgânico em supermercados na cidade do Natal-Brasil, os resultados da pesquisa revelaram que $43,5 \%$ dos entrevistados compram "quase sempre" ou "sempre" e apenas $8,1 \%$ "nunca" consumiram esse tipo de alimento. Essa estatística indica que o mercado de produtos orgânicos vem sendo uma boa oportunidade para produtores e varejistas, já que esse tipo de alimento possui um valor extra.

\section{Metodologia Aplicada}

Este artigo utilizou-se somente a pesquisa bibliográfica. Para Fonseca, "A pesquisa bibliográfica não é mera repetição do que já foi dito ou escrito sobre certo assunto" (FONSECA, 2007, p. 30). Neste aspecto mencionado pela autora Fonseca se pode dizer que este artigo buscou informações teóricas do tema tratado através de alguns autores justamente para entender sobre a produção orgânica e seu crescimento. 


\section{ReLAInEP}

Ainda para Fonseca as pesquisas bibliográficas devem "[...] propiciar o exame de um tema sob novo enfoque ou abordagem, que permitirá a elaboração de conclusões inovadoras" (FONSECA, 2007, p. 30).

De modo geral esta pesquisa também se utilizou de fontes secundária, isso porque as pesquisas bibliográficas são caracterizadas como sendo fontes secundárias. Ou seja, o material pesquisado surgiu de livros publicados caracterizando então como fontes secundárias.

De acordo com Gil (2001), não existem regras fixas para a realização de pesquisas bibliográficas, mas algumas tarefas que a experiência demonstra serem importantes. Dessa forma, seguiu-se o seguinte roteiro de trabalho:

a. Exploração das fontes bibliográficas: livros, revistas científicas, teses, relatórios de pesquisa entre outros, que contêm não só informação sobre determinados temas, mas indicações de outras fontes de pesquisa;

b. Leitura do material: conduzida de forma seletiva, retendo as partes essenciais para o desenvolvimento do estudo;

c. Elaboração de fichas: contém resumos de partes relevantes do material consultado;

d. Ordenação e análise das fichas: organizadas e ordenadas de acordo com o seu conteúdo, conferindo sua confiabilidade;

e. Conclusões: obtidas a partir da análise dos dados. O cuidado aqui observado diz respeito ao posicionamento neutro em relação ao problema pesquisado.
Ainda sobre a pesquisa bibliográfica, o estudo possui caráter exploratório, pois se utilizou de pesquisa bibliográfica em livros, artigo, sites e revistas e consistiu em explicar a temática utilizando o conhecimento disponível em teorias formuladas por pesquisadores sobre os pontos tratados (YIN, 2001).

$\mathrm{O}$ presente trabalho foi um estudo em uma Cooperativa de Produção Agropecuária Nova Santa Rita Ltda. - COOPAN, baseando-se em um estudo de caso direto, que de acordo a Serra (2006) é a apresentação de um caso real ou fictício para exercício de análise, em que são confrontados fundamentos teóricos com a prática exercida no local da pesquisa.

De acordo com Gil (2001) o estudo de caso vem sendo utilizado com frequência cada vez maior pelos pesquisadores sociais, visto servir a pesquisas com diferentes propósitos, tais como: explorar situações da vida real, cujos limites não estão claramente definidos; descrever a situação do contexto em que está sendo feita determinada investigação; e explicar as variáveis causais de determinado fenômeno, em situações muito complexas, que não possibilitam a utilização de levantamentos e experimentos.

\section{Conclusões}

Desta forma tendo em vista os argumentos apresentados durante todo o decorrer deste artigo verificou-se a importância desta inovação que é a produção orgânica e o crescimento que ela vem obtendo. 
Este artigo é mais uma referência para que sobre dele seja realizados estudos mais aprofundados sobre o crescimento e a viabilidade deste tipo de produção. Espera-se também que novos estudos sejam realizados sobre este tema tratado.

Por fim, os aspectos observados durante todo o decorrer deste artigo são de grande importância para produtores e organizações. Pois através da implantação desta inovação é uma solução para alguns agricultores obterem crescimento e para empresas uma opção de mercadoria que tem tudo para dar certo.

\section{Referências Bibliográficas}

ANDRADE, R. O. B.; TACHIZAWA, T.; CARVALHO, A. B. Gestão Ambiental: enfoque estratégico aplicado ao desenvolvimento sustentável. 2. ED. SÃO PAULO: MAKRON BOOKS, 2002.

ARUNDEL, ANTHONY ET AL. the future of innovation measurements in Europe: concepts, problems and practical directions. Disponível em: WWW.STEP.NO/PROJECTAREA/IDEA/PA PERS.HTML $>$. ACESSO EM MARÇO 2012.

BATEMAN, T. S.; SNELL, S. A. Administração: construindo vantagem competitiva. São Paulo: Atlas, 1998.

Brasil. Ministério da Agricultura, Pecuária e Abastecimento. Cadeia produtiva de produtos orgânicos. Ministério da Agricultura, Pecuária e Abastecimento, Secretaria de Política Agrícola, Instituto Interamericano de cooperação para a Agricultura; coordenadores Antônio Márcio Buainain e Mário Otávio Batalha. - Brasília: IICA: MAPA/SPA, 108, v. 5p. 17,5 x 24 cm - Agronegócios, 2007.

BRASIL. Ministério da Agricultura. Legislação Brasileira. Disponivel em: <http://www.prefiraorganicos.com.br/media/ 5806/lei_n-10831_de_23-12-2003.pdf >. Aces- so em: Abril/2012.

BRASIL. Ministério da Fazenda. Economia Brasileira em Perspectiva. Disponível em: <http://www.fazenda.gov.br/portugues/docs/ perspectiva-economia-brasileira/link.htm> Acesso em abril de 2012.

BRASIL. Lei $\mathbf{n}^{\circ} \mathbf{1 0 . 8 3 1}$, de 23 dezembro de 2003. Dispõe sobre a agricultura orgânica e dá outras providências. Disponível em: <http:// www.planetaorganico.com.br/lei23dez03.htm> . Acesso em: 20 de janeiro de 2006.

COOPAN - Cooperativa de Produção Agropecuária Nova Santa Rita Ltda. Disponível em: <http://www.coopanrs.com.br/produtos.php> Acesso em: 22 de outubro de 2012.

DAROLT, M. R. Vantagens e desvantagens dos principais canais de comercialização de produtos orgânicos. Disponível em: <http://www.ibd.com.br>. Acesso em: 19 de outubro de 2012.

DAVIS, M. M.; AQUILANO, N. J; CHASE, R. B. Fundamentos da administração de produção. 3. ed. Porto Alegre: Bookman, 2001.

FONSECA, Regina Célia Veiga da. Como elaborar projetos de pesquisa e monografias:guia prático. Curitiba: Imprensa Oficial, 2007.

GIL, Antônio Carlos. Como elaborar projetos de pesquisa. 4. ed. São Paulo: Atlas, 2002.

INSTITUTO DE ASSISTÊNCIATÉCNICA E EXTENSÃO RURAL DO RS Políticas. Disponível $\mathrm{em}:<$

http://www.emater.tche.br/site/sobre/> Acesso em: 20 de outubro de 2012.

JORDE, Thomas M. \& TEECE, David J. Competition and Cooperation: striking the right balance. California Management Review - Business \& Public Policy, Califórnia, spring 1989.

KEMP, René; PEARSON, Peter. Final report of the project Measuring Eco- Innovation. Maastricht, MEI (Measuring Eco-Innovation), 2007.

KISS, J. Terra em transe. Revista Globo Rural, São Paulo, n. 223, p. 34-41, maio 2004. 


\section{ReLAInEF}

NASSAR, A. M.. Certificação no agrobusiness. In: SEMINÁRIO Internacional PENSA de Agrobusiness: A Gestão da Qualidade dos Alimentos, 9ª Cap. 3, p. 16-30, 1998.

OECD/FAO. Agricultural Outlook 200829017: highlights, 2008. Disponível em: <HTTP://www.fao.org/es/esc/common/ecg /550/en/AgOut2017E.pdf $>$. Acesso em: 7 de jun. 2012.

OKUDA, T. Produção de alimento orgânico cresce 50\%. O Estado de São Paulo, 11 jun. 2002. Caderno Economia. Disponível em: < http: / / www.estadao.com.br/arquivo/economi a/2002/not20020611p31555.htm > Acesso em: 24 de outubro de 2012.

ORMOND, J. G. P.; PAULA, S. R. L.; ROCHA, L. T. M. Agricultura orgânica: quando o passado é futuro. BNDES Setorial, Rio de Janeiro, n. 15, p. 3-34, 2002. Disponível em: <http://www.bndes.gov.br/SiteBNDES/bndes/b ndes_pt/Institucional/Publicacoes/Consulta_Expre ssa/Setor/Agroindustria/200203_4.html > Acesso em: 25 de outubro de 2012.

Rio+20: Arroz ecológico de assentamento será vendido em rede de supermercados. Disponível em: <http://www.mda.gov.br/portal/noticiasriomais2 0/noticias/item?item_id=10057014> Acesso em: 22 de outubro de 2012.

RODRigues, A. C.; RODRIGUES, I. C. Análise do grau de conhecimento do consumidor diante da rotulagem de alimentos: um estudo preliminar. In: ENCONTRO NACIONAL DE ENGENHARIA DE PRODUÇÃO, 22, 2002, Curitiba. Anais... Paraná: ENEGEP, 2002.

SCHMIDT, W. Agricultura orgânica: entre a ética e o mercado? Agroecologia e Desenvolvimento Rural Sustentável. Revista online: Porto Alegre, v. 2, n. 1, p. 62-73, jan./mar. 2001.

SOUZA FILHO, H. M. S. Desenvolvimento agrícola sustentável. In: BATALHA, M. O. (Ed.). Gestão agroindustrial. São Paulo: Atlas, 2001. p. 585626.

SOUZA, M. C. M. Produtos orgânicos. In: NEVES; ZYLBERSZTAJN. Economia e gestão dos ne- gócios agroalimentares. São Paulo: Pioneira, 2000. p. 385-401.

STEVENSON, W. J. Administração das operações de produção. 6. ed. Rio de Janeiro: LTC, 2001 .

TACCONI, M. de F. F. da S. Estratégia de marketing ambiental no varejo de alimentos: um estudo sobre as variáveis utilizadas pelo consumidor na decisão de compra de produtos orgânicos. 2004. 89 f. Dissertação (Mestrado em Engenharia de Produção) - Universidade Federal do Rio Grande do Norte, Natal, 2004.

YIN, R. Estudo de caso: planejamento e métodos. Porto Alegre: Bookman, 2001. 